\title{
Indications for the use of human chorionic gonadotropic hormone for the management of infertility in hypogonadal men
}

\author{
John Alden Lee, Ranjith Ramasamy \\ Department of Urology, University of Miami Miller School of Medicine, Miami, FL, USA \\ Contributions: (I) Conception and design: All authors; (II) Administrative support: All authors; (III) Provision of study materials or patients: All \\ authors; (IV) Collection and assembly of data: All authors; (V) Data analysis and interpretation: All authors; (VI) Manuscript writing: All authors; (VII) \\ Final approval of manuscript: All authors. \\ Correspondence to: Ranjith Ramasamy, MD. Department of Urology, University of Miami Miller School of Medicine, 1120 NW 14th Street, Room \\ 1560, Miami, FL 33136, USA. Email: ramasamy@miami.edu.
}

\begin{abstract}
Hypogonadism among men desiring fertility preservation presents a unique challenge to physicians. Over the past decade the number of younger men with hypogonadism has increased dramatically. These men are often treated with testosterone replacement therapy (TRT) which can result in azoospermia and potentially infertility. Human chorionic gonadotropin (hCG) therapy can help re-establish or maintain spermatogenesis in hypogonadal men. We review the indications, and discuss the current evidence for the role of hCG in men with hypogonadisms.
\end{abstract}

Keywords: Human chorionic gonadotropin (hCG); hypogonadism; testosterone replacement therapy (TRT); hypogonadal hypogonadism; anabolic androgenic steroids (AAS); infertility

Submitted Jan 17, 2018. Accepted for publication Apr 09, 2018.

doi: $10.21037 /$ tau.2018.04.11

View this article at: http://dx.doi.org/10.21037/tau.2018.04.11

\section{Introduction}

The importance of the therapeutic human chorionic gonadotropin (hCG) treatment has grown tremendously over the last couple decades due to an exponential increase in the prevalence of hypogonadism in younger men and the use of anabolic androgenic steroids (AAS). From 2001 to 2011 men on testosterone replacement therapy (TRT) increased three fold overall and 4 times more among men aged 40-49 (1). The overall prevalence of hypogonadism in American men is $7 \%$ in men younger than 40 years and $38 \%$ in men over the age of $45(2,3)$. The use of AAS has been found to be as high as 3 million amongst American men (3) and have a life time of prevalence use of $3.0 \%$ to $4.2 \%$ (4). This increase has occurred along with steady increase in age of paternity (5) creating an evolving challenge of treating hypogonadism and preserving fertility.

Luteinizing hormone (LH) in the male is produced by the anterior pituitary in response to pulsatile secretion of gonadotropic releasing hormone $(\mathrm{GnRH})$ from the hypothalamus. It acts on Leydig cells in the testicles promoting the production of testosterone. In men with hypogonadotropic hypogonadism (HH), or men with decreased LH secondary to exogenous testosterone use, the lack of LH results in severely decreased intratesticular testosterone levels. Without intratesticular testosterone spermatogenesis is impaired, and by replacing lost $\mathrm{LH}$ production with hCG, spermatogenesis can be restored by restoring adequate levels of intratesticular testosterone.

hCG has also found a prominent role in treating endocrine failure of the testicle in men with anabolic steroid induced hypogonadism. These men have lost the ability to produce their own testosterone and hCG has been indicated as a part of an algorithm to help recover endogenous testosterone production (6).

Finally, hCG has also been used to reduce some of the side effects of TRT, mainly preventing testicular atrophy and helping maintain response to TRT by "cycling off" TRT with a periodic replacement of therapy with hCG. 


\section{Pharmacology of hCG}

hCG most prominent role in physiology is in that of maintaining early pregnancy. It is named from the Latin word chordata, meaning after birth, since it is primarily produced by the placenta. The first recognition of hCG as a gonadotropin was observed when human placental tissue was transplanted in rabbits and induced ovulation (7-9).

hCG is a hormone comprising of an $\alpha$ and a $\beta$-subunit. hCG and LH share an identical $\alpha$-subunit. hCG differs from LH in that its $\beta$-subunit has a highly glycosylated 24 amino acid tail. The side chain increases the receptor activity and slows the metabolism of hCG as compared to LH. This results in a half-life of 36 hours for hCG compared to 30 minutes for LH. The characteristics of sharing a receptor, having increased receptor activity, and a longer half-life make hCG an ideal pharmacological analog to LH.

\section{Indications for hCG in combination with TRT}

\section{Preserving spermatogenesis with TRT}

Exogenous steroid use impairs spermatogenesis by promoting negative feedback on both the hypothalamus and pituitary gland. This reduces the pulsatile secretion of GnRH and LH respectively. The loss of LH secretion shuts down the production of testosterone by Leydig cells which in turn significantly reduces intratesticular testosterone levels. This altering of the hypothalamus-pituitary-gonadal (HPG) axis and drop of intratesticular testosterone can lead to azoospermia within 10 weeks of starting TRT (10). Even more alarming is the fact that up to $10 \%$ of men can remain azoospermic after the cessation of TRT.

hCG therapy can help preserve spermatogenesis in men undergoing TRT by maintaining intratesticular testosterone levels. It was has been shown that follicle stimulating hormone (FSH) alone cannot initiate or maintain spermatogenesis in hypogonadal (11) men leading to the discovery of the importance of intratesticular testosterone in spermatogenesis. In healthy eugonadal men selected to undergo TRT it was shown that their intratesticular testosterone levels dropped by $94 \%$. However, in those who received 250 IU SC every other day along with TRT their intratesticular testosterone levels only dropped $7 \%$. Additionally, in men who received TRT and 500 IU of hCG every other day an increase in intratesticular testosterone by $26 \%$ was observed (12). This proved that co-administering low dose hCG could maintain intratesticular testosterone in those undergoing TRT. It was later shown that not only is intratesticular testosterone increased with co-administration hCG but spermatogenesis is preserved as well at one year follow up (13). These studies proved that by concomitant hCG administration with TRT spermatogenesis and thus potentially fertility could be preserved.

Based off this evidence an algorithm was suggested for the simultaneous treatment of hypogonadism and preservation of fertility (14). All men wishing to preserve fertility while on TRT should have a baseline semen analysis (SA). Next it is important to determine the appropriate dosing regimen of hCG based off the timeline for desired pregnancy. For men who wish to obtain pregnancy within six months it was suggested to discontinue TRT and start 3,000 IU of hCG intramuscular, or subcutaneous every other day. SA should then be performed every two months. Clomiphene citrate $25-50 \mathrm{mg}$ PO daily can be added or omitted to promote FSH production (15). We suggest including of clomiphene citrate in all men who are already oligospermic or azoospermic. It can be omitted in men who are initiating TRT and hCG simultaneously and have normal semen parameters.

If Semen parameters fail to improve and FSH remains low, Gonal-f (recombinant FSH) 75 IU every other day can be added. In men who desire pregnancy within 6-12 months TRT can be continued with co-administration of $500 \mathrm{IU}$ of HCG every other day \pm clomiphene citrate can be used. When planning for pregnancy in greater than 12 months TRT should be cycled off every six months replaced by a four-week cycle of 3,000 IU of hCG every other day. For men who do not desire to preserve fertility testicular size can me maintained while undergoing TRT with $1,500 \mathrm{IU}$ of HCG given weekly. Which is enough to maintain pre-TRT levels of intratesticular Testosterone (11). Table 1 summarizes recommendations for preserving spermatogenesis in men on TRT (16).

\section{Use of hCG for recovery of spermatogenesis in men using anabolic steroids}

While spontaneous recovery of spermatogenesis can occur with the cessation of TRT or AAS use alone, it can take several months to years. Median times for spermatogenesis to recover to thresholds of 20,10 , and 3 million per $\mathrm{mL}$ were $3.4,3.0$ and 2.5 months respectively. Sixty-seven percent of men recovered to a sperm concentrations of 20 million per $\mathrm{mL}$ within 6 months however some men took up to two years (17). The length of time to recovery of spermatogenesis is often too long for many patients who desire fertility. For these men hCG based treatments 
Table 1 Summary of recommendations for maintenance of spermatogenesis with TRT or AAS use

\begin{tabular}{|c|c|}
\hline $\begin{array}{l}\text { Timing of desired } \\
\text { pregnancy }\end{array}$ & Treatment recommendation \\
\hline \multirow[t]{4}{*}{$<6$ months } & Stop TRT/AAS \\
\hline & $\begin{array}{l}\text { Start 3,000 IU hCG every other day } \pm \\
\text { clomiphene citrate } 25 \mathrm{mg} \text { oral daily }\end{array}$ \\
\hline & Semen analysis every 2 months \\
\hline & $\begin{array}{l}\text { No FSH response: discontinue clomiphene } \\
\text { and add rhFSH } 75 \text { IU every other day }\end{array}$ \\
\hline \multirow[t]{2}{*}{$6-12$ months } & Continue TRT \\
\hline & $\begin{array}{l}\text { Start } 500 \text { IU hCG every other day } \pm \\
\text { clomiphene citrate } 25 \mathrm{mg} \text { oral daily }\end{array}$ \\
\hline \multirow[t]{2}{*}{$>12$ months } & Continue TRT \\
\hline & $\begin{array}{l}\text { Cycle off TRT/AAS every } 6 \text { months with a } \\
\text { 4-week cycle of } 3,000 \text { IU hCG every other day }\end{array}$ \\
\hline
\end{tabular}

TRT, testosterone replacement therapy; AAS, anabolic androgenic steroids; hCG, human chorionic gonadotropin; FSH, follicle stimulating hormone; rhFSH, recombinant human $\mathrm{FSH}$.

have been used to induce spermatogenesis sooner. A review performed showed that most treatment regimens consist of starting with hCG only doses of 1,500 to 5,000 IU 2-3 times per week for three to six months and then adding recombinant FSH in doses of 75 to 400 IUs 2-3 times per week in men who did not regain spermatogenesis on hCG alone (18). Specifically, a multi-institutional study showed that azoospermic or severely oligospermic men who had previously used TRT and treated with hCG 3,000 IU every other day supplemented with either anastrozole, clomiphene citrate, FSH or tamoxifen were able to regain spermatogenesis to a concentration of 22 million per $\mathrm{mL}$ with mean time of 4 months (15).

A proposed algorithm consists of stopping testosterone use and obtaining baseline SA, and hormones (FSH, LH, $\mathrm{T}$, estradiol). It is important to consider cryopreservation at any point the patient is found to have improved to oligospermic counts during treatment. Treatment should be initiated with hCG 2,000 IU every other day and clomiphene citrate $50 \mathrm{mg}$ PO every other day. After 3 months SA and hormones should be repeated. If estradiol is high, then anastrozole $1 \mathrm{mg}$ PO twice weekly can be added. If azoospermia or severe oligospermia persist then FSH 75 IU every other day should be added. If the next SA at three months has persistent azoospermia, then testicular sperm extraction (TESE)/micro TESE should be considered. Figure 1 contains a summary of recommendations for initiating spermatogenesis in men using AAS or TRT (16).

\section{Use of hCG in men with HH}

$\mathrm{HH}$ can be caused by congenital GnRH deficiency that can be classified as Kallmann's syndrome and normosmic idiopathic hypogonadotropic hypogonadism (IHH). HH occurs with an estimated prevalence that ranges from $1: 10,000$ to $1: 86,000$ individuals (19). Rarely HH can be caused by hemochromatosis, and sarcoidosis of the pituitary, or other lesions to the HPG axis. These lesions include pituitary adenomas and other central nervous system tumors. While less prevalent, the impact of hCG therapy is just as great, as these men were once deemed infertile and now can regain spermatogenesis with hCG therapy.

While $\mathrm{HH}$ is far less common these men can successfully regain fertility with treatments similar to that for hypogonadal men. Formerly GnRH infusion pumps were used to deliver a pulsatile release of GnRH. This method of therapy has fallen out of favor primarily due to cost and the inconvenience of having to wear a pump. Also this type of therapy requires a functioning pituitary on which GnRH can act and therefore it will only be helpful in men who have HH secondary to hypothalamic failure only. This has resulted in the primary use of gonadotropins to treat infertility in men with $\mathrm{HH}$ as it has been shown to induce spermatogenesis (20). The regimens used to treat men with HH usually consist of hCG 1,500-2,000 IU 2-3 times weekly to achieve at testosterone level within the normal range. If this alone fails to induce spermatogenesis within 4-6 months FSH 75 IU SC every other day can be added (21). It is important to note that it can take up to 2 years on this regimen to reach maximum sperm production. Factors that can predict higher rate of response to therapy include larger baseline testicular size, postpubertal onset of $\mathrm{HH}$, and low body mass index (19). An important omission in the treatment of men with $\mathrm{HH}$ is to not use clomiphene citrate as it will have no effect with non-functioning hypothalamus.

\section{Use of hCG to promote spermatogenesis in men with infertility}

hCG also has been shown to have a role in hormonally optimizing men with non-obstructive azoospermia to improve sperm retrieval. A multicenter study demonstrated that increasing FSH by 1.5 times it initial level and 


\section{Steroid induced hypogonadotropism and infertility}

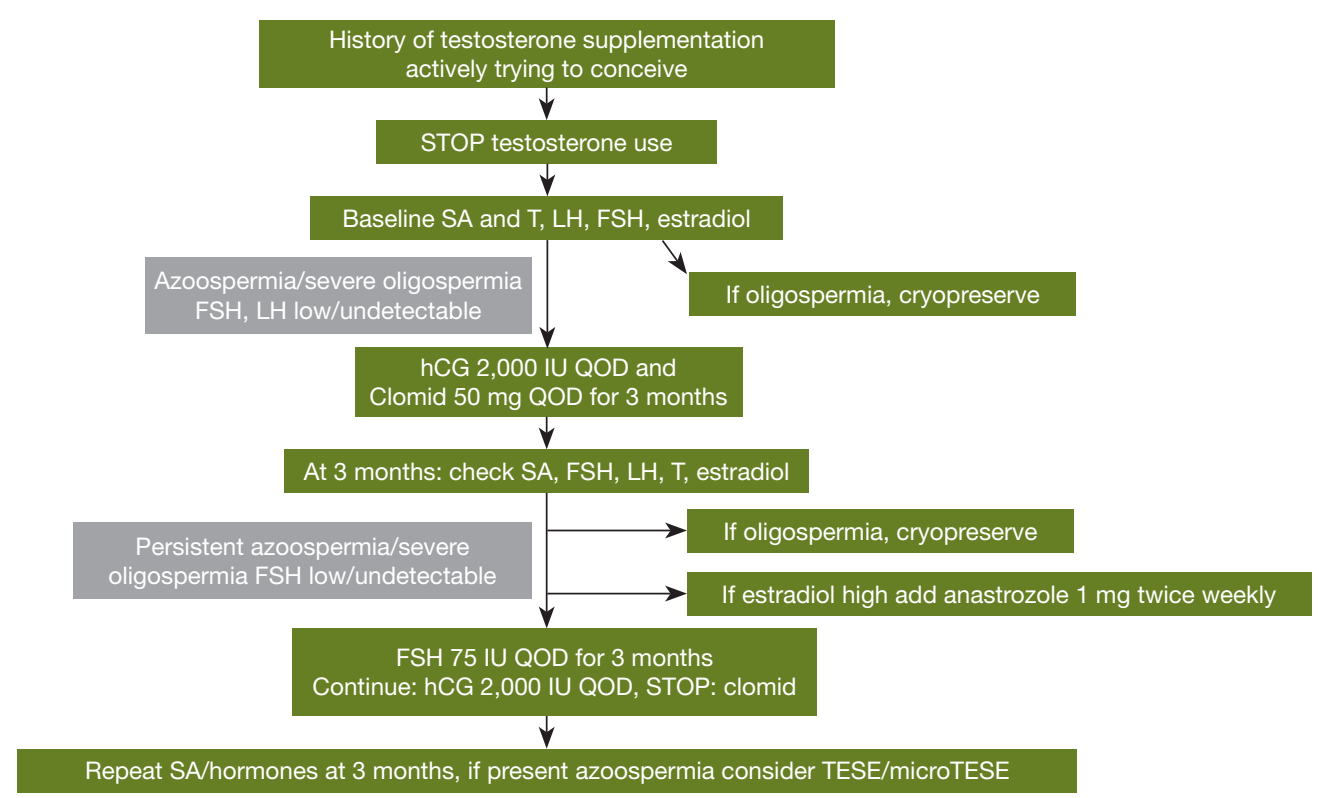

Figure 1 Algorithm for the treatment of steroid induced infertility. SA, semen analysis; T, testosterone; LH, luteinizing hormone; FSH, follicle stimulating hormone; hCG, human chorionic gonadotropin; TESE, testicular sperm extraction.

testosterone to $600-800 \mathrm{ng} / \mathrm{dL}$ increased chances of sperm in the ejaculate or in sperm retrieval at the time of TESE. Patients were treated with clomiphene citrate, and in men who did not have increased LH or testosterone levels hCG was added to their treatment regimen at a dose of 5,000 IU weekly. Men who failed to have an increase in FSH were also given human menopausal hormone. Overall $11 \%$ men were able to have sperm in the ejaculate and the rate of successful sperm retrieval with TESE was $57 \%$ compared to $33.6 \%$ in non-medically treated controls (22).

Similarly, sperm retrieval in men with non-mosaic Klinefelter's syndrome and hypogonadism is more successful with medical therapy to treat hypogonadism (23). Men with non-mosaic Klinefelter's syndrome with testosterone levels less than 250 and that responded to medical therapy with either clomiphene citrate, aromatase, or hCG had $77 \%$ sperm retrieval rate during testicular microdissection compared to $55 \%$ in men who did not respond.

\section{Conclusions}

As the age of men with hypogonadism continues to decrease and the age of paternity continues to increase more men will need to treatment for hypogonadism while maintaining fertility. hCG is a safe and efficacious alternative or adjunct to TRT in men desiring to preserve fertility while treating their hypogonadism. hCG can also be used help restore spermatogenesis in men hypogonadal hypogonadism or steroid induced impairment of spermatogenesis.

\section{Acknowledgements}

Figures reprinted/adapted by permission from Springer Nature. Terms and Conditions for RightsLink Permissions Springer Customer Service Centre GmbH: Springer Nature, The Complete Guide to Male Fertility Preservation by Ahmad Majzoub and Ashok Agarwal, Chapter 9, Fertility Preservation in Hypogonadal Men by Robert J. Carrasquillo and Ranjith Ramasamy 2017.

\section{Footnote}

Conflicts of Interest: The authors have no conflicts of interest to declare.

\section{References}

1. Baillargeon J, Urban RJ, Ottenbacher KJ, et al. Trends in androgen prescribing in the United States, 2001 to 2011. JAMA Intern Med 2013;173:1465-6. 
2. Rohrmann S, Platz EA, Selvin E, et al. The prevalence of low sex steroid hormone concentrations in men in the Third National Health and Nutrition Examination Survey (NHANES III). Clin Endocrinol (Oxf) 2011;75:232-9.

3. Mulligan T, Frick MF, Zuraw QC, et al. Prevalence of hypogonadism in males aged at least 45 years: the HIM study. Int J Clin Pract 2006;60:762-9.

4. Fronczak CM, Kim ED, Barqawi AB. The insults of illicit drug use on male fertility. J Androl 2012;33:515-28.

5. Kovac JR, Addai J, Smith RP, et al. The effects of advanced paternal age on fertility. Asian J Androl 2013;15:723-8.

6. Rahnema CD, Lipshultz LI, Crosnoe LE, et al. Anabolic steroid-induced hypogonadism: diagnosis and treatment. Fertil Steril 2014;101:1271-9.

7. Aschner B. Ueber die function der hypophyse. Pflug Arch Gest Phsiol 1912;146:1-147.

8. Fellner OO. Experimentelle untersuchungen über die wirkung von gewebsextrakten aus der Plazenta und den weiblichen Sexualorganen auf das Genitale. Arch Gynakal 1913:100:641.

9. Hilrose T. Experimnetelle histologische studie zure genese corpus luteum. Mitt Med Fakultd Unive ZU 1919;23:63-70.

10. Contraceptive efficacy of testosterone-induced azoospermia in normal men. World Health Organization Task Force on methods for the regulation of male fertility. Lancet 1990;336:955-9.

11. Schaison G, Young J, Pholsena M, et al. Failure of combined follicle-stimulating hormone-testosterone administration to initiate and/or maintain spermatogenesis in men with hypogonadotropic hypogonadism. J Clin Endocrinol Metab 1993;77:1545-9.

12. Coviello AD, Matsumoto AM, Bremner WJ, et al. Low-dose human chorionic gonadotropin maintains intratesticular testosterone in normal men with testosterone-induced gonadotropin suppression. J Clin Endocrinol Metab 2005;90:2595-602.

13. Hsieh TC, Pastuszak AW, Hwang K, et al. Concomitant intramuscular human chorionic gonadotropin preserves

Cite this article as: Lee JA, Ramasamy R. Indications for the use of human chorionic gonadotropic hormone for the management of infertility in hypogonadal men. Transl Androl Urol 2018;7(Suppl 3):S348-S352. doi: 10.21037/tau.2018.04.11 spermatogenesis in men undergoing testosterone replacement therapy. J Urol 2013;189:647-50.

14. Ramasamy R, Armstrong JM, Lipshultz LI. Preserving fertility in the hypogonadal patient: an update. Asian J Androl 2015;17:197-200.

15. Wenker EP, Dupree JM, Langille GM, et al. The Use of HCG-Based Combination Therapy for Recovery of Spermatogenesis after Testosterone Use. J Sex Med 2015;12:1334-7.

16. Carrasquillo R, Ramasamy R. Fertility Preservation in Hypogonadal Men. In: Majzoub A, Agarwal A. editors. The Complete Guide to Male Fertility Preservation. Springer Nature, 2017:105-21.

17. Liu PY, Swerdloff RS, Christenson PD, et al. Rate, extent, and modifiers of spermatogenic recovery after hormonal male contraception: an integrated analysis. Lancet 2006;367:1412-20.

18. McBride JA, Coward RM. Recovery of spermatogenesis following testosterone replacement therapy or anabolicandrogenic steroid use. Asian J Androl 2016;18:373-80.

19. Hayes FJ, Seminara SB, Crowley WF Jr. Hypogonadotropic hypogonadism. Endocrinol Metab Clin North Am 1998;27:739-63, vii.

20. Sokol RZ. Endocrinology of male infertility: evaluation and treatment. Semin Reprod Med 2009;27:149-58.

21. Warne DW, Decosterd G, Okada H, et al. A combined analysis of data to identify predictive factors for spermatogenesis in men with hypogonadotropic hypogonadism treated with recombinant human folliclestimulating hormone and human chorionic gonadotropin. Fertil Steril 2009;92:594-604.

22. Hussein A, Ozgok Y, Ross L, et al. Optimization of spermatogenesis-regulating hormones in patients with non-obstructive azoospermia and its impact on sperm retrieval: a multicentre study. BJU Int 2013;111:E110-4.

23. Ramasamy R, Ricci JA, Palermo GD, et al. Successful fertility treatment for Klinefelter's syndrome. J Urol 2009;182:1108-13. 